\title{
Karakteristik Struktur Mikro dan Gugus Fungsi Komposit Silika Sekam Padi dan Aspal
}

\author{
Ediman Ginting Suka ${ }^{(1)^{*}}$, Ira Sudarsono Putri, Reka Puspitasari, Reza Arsela, \\ Iqbal Firdaus, Simon Sembiring
}

Jurusan Fisika, Fakultas Matematika dan Ilmu Pengetahuan Alam (FMIPA), Universitas Lampung, Bandar Lampung, 35141

*ediman.ginting@fmipa.unila.ac.id; simonsembiring2@gmail.com

Diterima (26 September 2019), Direvisi (4 Nopember 2019)

\begin{abstract}
Composite of rice husk and asphalt silica was carried out at a ratio of 1: 0.7; 1: 0.8 and 1: 0.9 and heated at $150^{\circ} \mathrm{C}$ for 3 hours. The characteristics of the phase structure, microstructure, and functional groups were analyzed using X-ray Diffraction (XRD), Scanning Electron Microscopy-Energy Dispersive Spectroscopy (SEM-EDS) and Fourier Transform Infrared (FTIR), physical properties analysis (density, porosity) and mechanics (compressive strength). The XRD results showed that the phase in asphalt silica composites detected amorphous carbon at $2 \theta=18^{\circ}$ and amorphous silica with the amorphous silica peak shifted from $2 \theta=22^{\circ}$ to $2 \theta=20^{\circ}$. Microstructure analysis shows that cracks and clusters are bigger with grain sizes of 7,742 $\mu \mathrm{m}$, $8,495 \mu \mathrm{m}$ and 10,921 $\mathrm{\mu m}$ respectively, and the sample composition shows percentage of silicon (Si), Oxygen $(\mathrm{O})$ and sodium $(\mathrm{Na})$, respectively. decreases and the percentage of carbon $(\mathrm{C})$, sulfur $(\mathrm{S})$ increases. The results of FTIR show that the functional groups of $\mathrm{Si}-\mathrm{OH}$, $\mathrm{Si}$-O-Si and $\mathrm{Si}-\mathrm{O}$ bonds are decreasing and the functional groups of $\mathrm{C}-\mathrm{H}$ bonds are increasing. The addition of asphalt causes the value of density increases, the value of porosity and compressive strength decreases.
\end{abstract}

Keywords: asphalt, functional groups, rice husks, silica, structure

Abstrak. Komposit silika sekam padi dan aspal dilakukan pada perbandingan komposisi massa 1:0,7; 1:0,8; 1:0,9 dan dipanaskan pada suhu $150^{\circ} \mathrm{C}$ selama 3 jam. Karakteristik struktur fasa, struktur mikro, dan gugus fungsi dianalisis menggunakan $X$-ray Diffraction (XRD), Scanning Electron Microscopy-Energy Dispersive Spectroscopy (SEM-EDS) dan Fourier Transform Infrared (FTIR), analisis sifat fisis (densitas, porositas) dan mekanik (kuat tekan). Hasil XRD menunjukkan fasa pada komposit silika aspal terdeteksi karbon amorf pada $2 \theta$ sebesar $18^{\circ}$ dan silika amorf dengan puncak silika amorf bergeser dari $2 \theta=22^{\circ}$ menjadi $2 \theta=20^{\circ}$. Analisis struktur mikro menunjukkan adanya retakan (cracking) serta gumpalan (cluster) semakin besar dengan ukuran butir masing-masing 7,742 $\mu \mathrm{m}, 8,495 \mu \mathrm{m}$ dan 10,921 $\mu \mathrm{m}$ serta komposisi sampel menunjukkan persentase kadar silikon ( $\mathrm{Si})$, Oksigen $(\mathrm{O})$ dan natrium $(\mathrm{Na})$ semakin menurun dan persentase kadar karbon $(\mathrm{C})$, sulfur $(\mathrm{S})$ semakin meningkat. Hasil FTIR menunjukkan gugus fungsi ikatan $\mathrm{Si}-\mathrm{OH}, \mathrm{Si}-\mathrm{O}-\mathrm{Si}$ dan $\mathrm{Si}-\mathrm{O}$ semakin menurun dan gugus fungsi dari ikatan $\mathrm{C}-\mathrm{H}$ semakin meningkat. Penambahan aspal menyebabkan nilai densitas meningkat, nilai porositas dan kuat tekan menurun.

Kata kunci: aspal, gugus fungsi, sekam padi, silika, struktur

\section{PENDAHULUAN}

Indonesia memiliki sekam padi yang melimpah dan masih belum termanfaatkan dengan baik. Sekam padi memiliki kandungan silika yang cukup tinggi yaitu sebesar 94,66\% [1]. Penelitian yang telah dilakukan oleh Bakar et al. (2016) menjelaskan bahwa kandungan silika yang diperoleh dari sekam padi sebesar 99\%. Tingginya kandungan silika dari sekam padi 
sehingga dapat dimanfaatkan sebagai bahan baku alternatif sumber silika.

Silika sekam padi dapat diperoleh dengan beberapa metode yaitu metode ekstraksi alkalis dan metode pengabuan. Secara umum metode pengabuan didasarkan pada karakteristik tingkat pembentukan kristalinitas silika melalui proses perlakuan termal, sementara metode alkalis didasarkan pada tingkat kelarutan silika yang tinggi dalam larutan alkalis seperti $\mathrm{KOH}, \mathrm{Na}_{2} \mathrm{CO}_{3}$, atau $\mathrm{NaOH}$ dan pengendapan silika terlarut mengggunakan asam seperti asam klorida, asam sitrat, asam asetat, dan asam oksalat. Metode alkalis telah banyak digunakan dalam ekstraksi silika dari sekam padi, hal ini dikarenakan prosesnya yang sederhana dan biaya yang murah.

Peneliti telah menggunakan material silika sekam padi sebagai bahan baku pembuatan cordierite [2] dan mullite [3]. Selain itu, komposit dari silika sekam padi juga telah digunakan seperti karet alam [4], rubber [5], kitosan [6], dan selulosa asetat [7]. Material lain yang dapat digunakan sebagai komposit dari silika sekam padi adalah aspal [8].

Aspal merupakan material perekat, berwarna hitam atau coklat tua dengan unsur utama bitumen. Komposisi aspal terdiri dari asphaltenes dan malthenes. Asphaltenes mengandung karbon (82-88\%), hidrogen (8$11 \%)$, sulfur $(0-6 \%)$, oksigen $(0-1,5 \%)$, dan nitrogen (0-1\%). Malthenes terdapat tiga komponen penyusun yaitu resin, aromatic, dan saturates.

Komposit aspal telah banyak dikembangkan seperti menggunakan partikel silika [9] dan nanosilika [10]. Penelitian Enieb and Diab pencampuran aspal dengan penambahan nanosilika pada konsentrasi (2, 4 dan $6 \mathrm{wt} \%)$ diperoleh hasil dengan penambahan nanosilika dapat meningkatkan titik lembek, viskositas, kuat tarik, anti-penuaan, kinerja retak lelah, dan tahan terhadap kelembaban [10]. Menurut penelitian Budiawati penambahan silika terhadap aspal menyebabkan puncak asphaltene tertutupi oleh munculnya puncak silika amorf dan karbon amorf [11], puncak vibrasi dari gugus $\mathrm{C}-\mathrm{O}$ dan $\mathrm{S}-\mathrm{O}$ semakin melemah seiring dengan penambahan silika terhadap aspal [12].

Berdasarkan uraian di atas, penelitian ini dilakukan mengenai komposit silika dari sekam padi dan aspal. Penelitian ini bertujuan untuk mengetahui struktur fasa, struktur mikro, gugus fungsi, sifat fisis (densitas, porositas) dan mekanik (kuat tekan). Perbandingan massa silika dan aspal yang digunakan yaitu 1:0,7; 1:0,8 dan 1:0,9. Pada penelitian ini dilakukan analisis struktur fasa dengan $X$-ray Diffraction (XRD), struktur mikro menggunakan Scanning Electron Microscopy - Energy Dispersive Spectroscopy (SEM-EDS), gugus fungsi dengan Fourier Transform Infrared (FTIR), analisis sifat fisis meliputi densitas, porositas dan mekanik yaitu kuat tekan menggunakan compression testing machine (MTS Landmark).

\section{METODE PENELITIAN}

Alat yang digunakan adalah beaker glass, gelas ukur, tabung erlenmayer, neraca digital, aluminum foil, $\mathrm{pH}$ indikator (Merck Universal Paper), spatula, batang pengaduk, tisu, kompor listrik, plastik Cling Wrap, mortar dan pestle, corong bucher, hot plate stirrer, magnetic bar, cawan porselin, wadah sampel, stopwatch, kertas saring, oven, ayakan 150 dan 250 mesh, Hydrolic Press (GASEBY SPECAC), XRD (X'Pert PRO PANalytical), SEM-EDS (TESCAN VEGA3) dan FTIR (Nicolet iS10 Spectrometer). Bahan yang digunakan adalah sekam padi, natrium hidroksida $(\mathrm{NaOH})$ $99 \%$, asam nitrat $\left(\mathrm{HNO}_{3}\right) 68 \%$, akuades, bensin, dan aspal 60/70. 


\section{Ekstraksi Silika Sekam Padi}

Sekam padi terlebih dahulu dibersihkan, dan direndam air selama 1 jam. Sekam padi yang tenggelam diambil dan direndam dengan air panas selama 6 jam, hal ini dimaksudkan untuk menghilangkan kotoran-kotoran (zat organik) yang larut dalam air seperti tanah, pasir, debu, dan zat pengotor lain terlepas dari sekam padi. Setelah itu, sekam padi dijemur hingga kering. Setelah sekam padi dipreparasi, selanjutnya diekstraksi dengan metode ekstraksi alkalis. Sekam padi ditimbang sebanyak 50 gram, kemudian ditambahkan larutan $\mathrm{NaOH}$ 1,5\% sebanyak $500 \mathrm{ml}$. Selanjutnya dipanaskan hinggga mendidih dan kemudan didiamkan selama 24 jam dan diperoleh sol silika. Ekstrak sol silika kemudian ditetesi menggunakan larutan $\mathrm{HNO}_{3} 10 \%$ sebanyak $100 \mathrm{ml}$ hingga menjadi gel silika dan mencapai $\mathrm{pH}$ 7. Gel silika yang berwarna coklat, selanjutnya dicuci dengan akuades hangat dan disaring menggunakan kertas saring hingga gel silika berwarna putih. Gel silika kemudian dioven pada suhu $110^{\circ} \mathrm{C}$ selama \pm 3 jam hingga kering dan diperoleh silika padatan. Silika digerus dengan menggunakan mortar dan pastel hingga menjadi serbuk silika dan berwarna putih. Serbuk silika yang sudah digerus kemudian diayak 250 mesh untuk mendapatkan serbuk silika yang halus dan homogen.

\section{Preparasi Komposit Silika Aspal}

Komposit silika aspal pada penelitian ini dengan perbandingan massa silika aspal yaitu $1: 0,7 ; 1: 0,8$ dan 1:0,9. Pembuatan komposit silika aspal dengan menimbang aspal sebanyak 3,5; 4 dan 4,5 gram kemudian dilarutkan dengan bensin $30 \mathrm{ml}$ sambil diaduk dan dipanaskan dengan hot plate stirrer pada suhu $160{ }^{\circ} \mathrm{C}$. Setelah aspal mencair ditambahkan serbuk silika sebanyak 5 gram dan diaduk dengan spatula hingga homogen sehingga diperoleh serbuk silika aspal berwarna coklat kehitaman.

Setelah itu dilakukan pengeringan sampel komposit silika aspal dengan menggunakan oven selama \pm 3 jam pada suhu $150{ }^{\circ} \mathrm{C}$. Selanjutnya sampel digerus dengan mortar dan pastel. Sampel yang sudah digerus kemudian diayak 150 mesh untuk mendapatkan serbuk komposit silika aspal. Kode sampel yang digunakan untuk silika sekam padi adalah SA0 dan paduan silika aspal berturut-turut adalah SA07; SA08 dan SA09.

\section{HASIL DAN PEMBAHASAN}

\section{Karakterisasi XRD}

Karakterisasi XRD dilakukan untuk mengetahui struktur fasa pada sampel. Hasil difraktogram menunjukkan sampel SA0, SA07, SA08 dan SA09 memiliki fasa amorf. Pada sampel SA0 memiliki puncak intensitas tertinggi pada $2 \theta$ sebesar $22^{\circ}$, hal ini sesuai dengan penelitian [13-15] yang menunjukkan bahwa keberadaan silika amorf dengan puncak intensitas tertinggi pada $2 \theta$ sebesar $22^{\circ}$. Sampel SA07, SA08, dan SA09 menunjukkan terbentuknya puncak silika dan karbon. Adanya silika dan karbon pada penambahan aspal mengindikasikan bahwa aspal telah berinteraksi dengan silika.

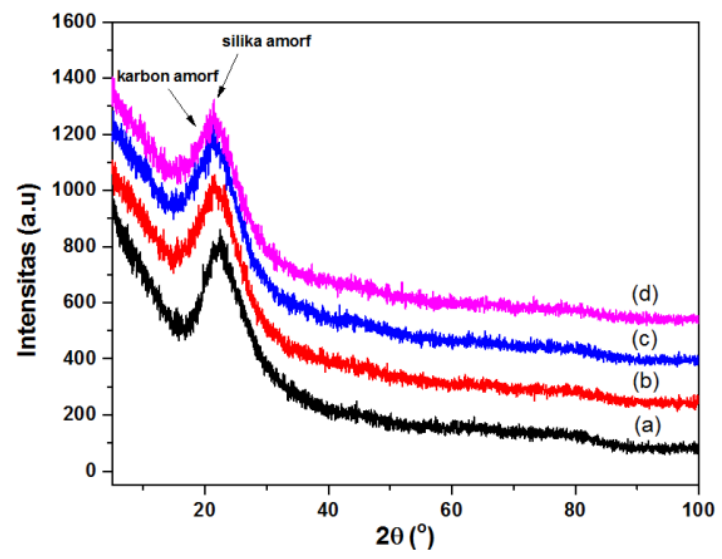

Gambar 1. Difraktogram sampel (a) SA0, (b) SA 07, (c) SA08 dan (d) SA09 
Silika amorf teridentifikasi dengan puncak intensitas tertinggi pada $2 \theta$ sebesar $20^{\circ}$. Penambahan aspal menyebabkan perubahan puncak silika amorf dari $2 \theta$ sebesar $22^{\circ}$ menjadi $2 \theta$ sebesar $20^{\circ}$. Hal ini disebabkan karena adanya puncak karbon amorf pada penambahan aspal. Puncak karbon amorf terdapat pada $2 \theta$ sebesar $18^{\circ}$, hal ini sesuai dengan penelitian Nazari et al., 2018 bahwa hasil XRD dari sampel menunjukkan puncak karbon berada pada $2 \theta$ sebesar $18^{\circ}[16]$.

\section{Karakterisasi SEM-EDS}

Karakterisasi SEM-EDS dilakukan untuk mengetahui struktur mikro dan komposisi unsur pada sampel. Hasil morfologi SEM pada sampel SA07 terlihat bahwa struktur mikro permukaan terdapat butiran-butiran kecil yang terdistribusi tidak merata pada permukaan, adanya retakan (cracking) serta terdapat gumpalan (cluster) yang cukup beragam. Adanya gumpalan menunjukkan bahwa silika tertutupi oleh aspal sehingga ukuran butir menjadi besar [17]. Ukuran rata-rata butir yaitu sebesar $7,742 \mu \mathrm{m}$. Sampel SA08 menunjukkan adanya retakan lebih banyak dan terdapat gumpalan dengan ukuran rata-rata butir sebesar 8,495 $\mu \mathrm{m}$. Sampel SA09 terlihat adanya gumpalan yang lebih besar dengan ukuran rata-rata butir sampel SA09 sebesar $10,921 \mu \mathrm{m}$.

Hasil analisis EDS sampel SA07 menunjukkan adanya unsur karbon (C), silikon $(\mathrm{Si})$, sulfur $(\mathrm{S})$, oksigen $(\mathrm{O})$ dan natrium (Na). Menurut Ningtias (2018) bahwa komposisi aspal terdiri dari unsur karbon, sulfur, oksigen, alumunium dan kalsium yang didominasi unsur karbon dengan persentase massa sebesar $91,63 \%$ [18]. Selain itu, dari hasil EDS terdapat unsur natrium. Kehadiran natrium berasal dari ekstraksi silika sekam padi dengan menggunakan pelarut $\mathrm{NaOH}$.
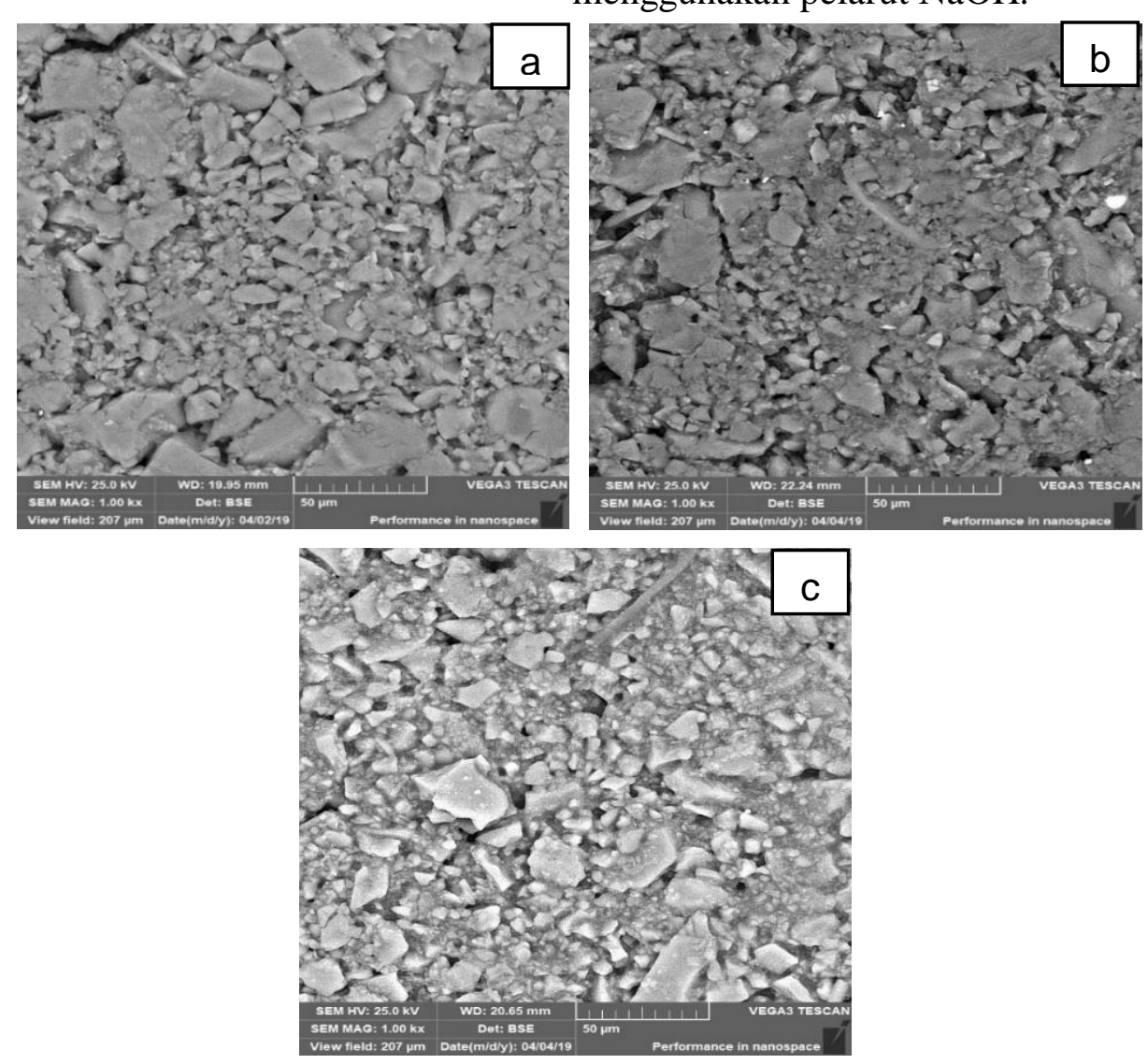

Gambar 2. Morfologi SEM (a) SA07; (b) SA08; (c) SA09 
Tabel 1. Komposisi sampel dari hasil analisis EDS

\begin{tabular}{llllll}
\hline & \multicolumn{5}{c}{ Massa (\%) } \\
\cline { 2 - 6 } Sampel & $\mathrm{C}$ & $\mathrm{Si}$ & $\mathrm{S}$ & $\mathrm{O}$ & $\mathrm{Na}$ \\
\hline SA07 & 45,01 & 21,92 & 3,47 & 29,05 & 0,42 \\
SA08 & 50,29 & 19,88 & 3,60 & 25,44 & 0,66 \\
SA09 & 52,84 & 18,27 & 3,74 & 25,42 & - \\
\hline
\end{tabular}

Pada sampel SA08 menunjukkan adanya unsur karbon, silikon, sulfur, oksigen dan natrium. Dengan adanya penambahan aspal menyebabkan unsur karbon meningkat dari 45,01\% menjadi 50,29\% dan unsur silikon menurun dari $21,92 \%$ menjadi $19,88 \%$. Pada sampel SA0,9 terlihat adanya unsur karbon, silikon, sulfur dan oksigen.

Komposisi pada sampel SA 0,9 berbeda dengan sampel sebelumnya yang menunjukkan unsur natrium sudah tidak ada. Hal ini disebabkan karena penambahan aspal yang lebih banyak sehingga unsur natrium tertutupi oleh aspal. Penambahan aspal juga menyebabkan persentase massa unsur karbon meningkat dari sampel sebelumnya yaitu dari 50,29\% menjadi $52,84 \%$ dan persentase unsur silikon menurun dari $19,88 \%$ menjadi $18,27 \%$.

\section{Karakterisasi FTIR}

Karakterisasi FTIR dilakukan dengan tujuan untuk mengetahui gugus fungsi pada suatu material yang terdapat pada sampel. Hasil FTIR yang diperoleh berupa grafik hubungan antara bilangan gelombang dan transmitan. Analisis karakterisasi FTIR pada sampel SA0; SA07; SA08; dan SA09 memperlihatkan gugus fungsi yang sama yaitu $\mathrm{Si}-\mathrm{OH}, \mathrm{O}-\mathrm{H}, \mathrm{Si}-\mathrm{O}-\mathrm{Si}$, dan $\mathrm{Si}-\mathrm{O}$ pada bilangan gelombang berturut-turut yaitu, $3448,72 \mathrm{~cm}^{-1}, 1651 \mathrm{~cm}^{-1}, 1103 \mathrm{~cm}^{-1}, 802,39$ $\mathrm{cm}^{-1}$, dan 470,6 $\mathrm{cm}^{-1}$. Spektrum yang dihasilkan menunjukkan adanya gugus fungsi baru yaitu $\mathrm{C}-\mathrm{H}$ yang sebelumnya tidak ada pada spektrum sampel SA0.

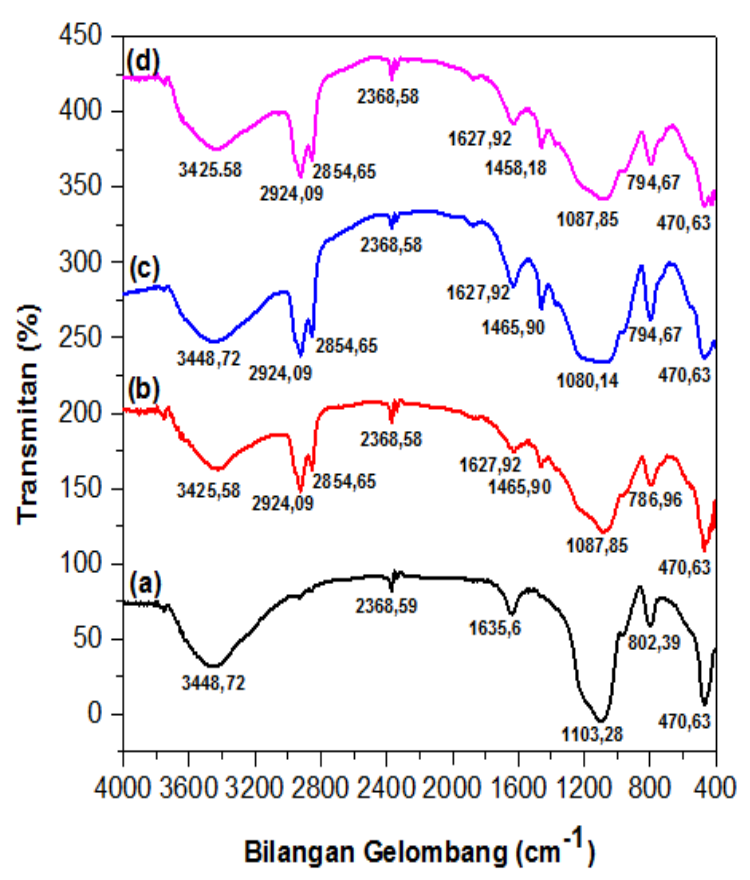

Gambar 3. Spektrum FTIR (a) SA0; (b) SA07; (c) SA08; dan (d) SA09.

Gugus fungsi $\mathrm{C}-\mathrm{H}$ mulai terbentuk pada bilangan gelombang 2924,09 $\mathrm{cm}^{-1}, 2854,65$ $\mathrm{cm}^{-1}$ dan didukung vibrasi tekuk pada bilangan gelombang $1465,90 \mathrm{~cm}^{-1}$. Hadirnya gugus fungsi C-H menandakan gugus fungsi utama munculnya aspal. Hal ini mengindikasikan bahwa silika dengan aspal sudah tercampur. Hasil ini sesuai dengan penelitian yang dilakukan oleh Costa and Paronhos [19-21].

\section{Uji Densitas dan Porositas}

Analisis sifat fisis (densitas dan porositas) dilakukan untuk mengetahui kerapatan dan persen pori pada silika aspal. Hasil pengukuran densitas dan porositas menunjukkan bahwa dengan penambahan aspal nilai densitas meningkat, sedangkan nilai porositas menurun. Densitas pada umumnya dipengaruhi oleh suhu pemadatan proses pemadatan, dan gradasi (termasuk di dalamnya bentuk agregat yang digunakan). 


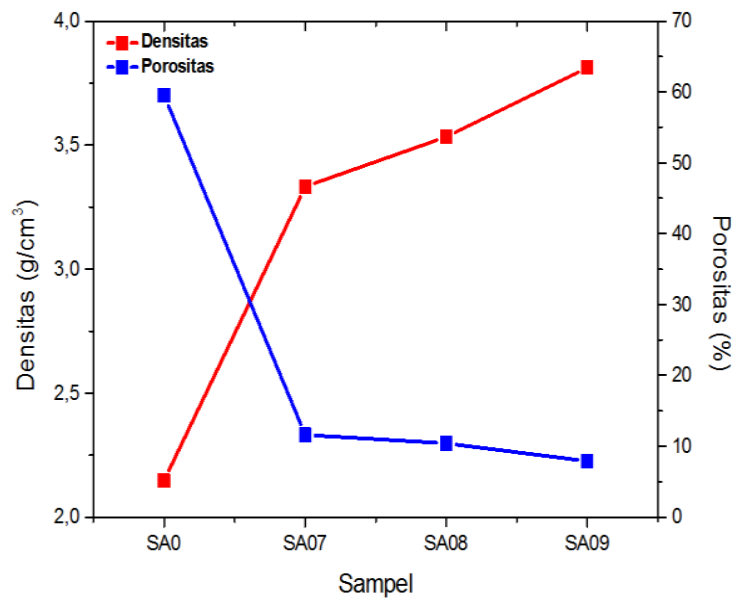

Gambar 4. Grafik uji densitas dan porositas

Peningkatan densitas disebabkan karena kandungan kadar aspal yang berbeda maka volume campuran berbeda pula, peningkatan kadar aspal sampai kadar tertentu mengakibatkan campuran lebih mudah dipadatkan dan berat isi campuran makin meningkat serta dalam rongga dalam campuran makin menurun. Meningkatnya rongga dalam agregat pada kadar aspal tertentu dikarenakan rongga dalam agregat yang makin padat diisi oleh aspal yang kemudian aspal mendorong butir-butir agregat [22].

Peningkatan densitas juga telah terjadinya proses pemadatan (densifikasi) yang memungkinkan terjadinya perubahan struktur dan mikrostruktur, dimana partikelpartikel saling mengikat sehingga ukuran butiran menjadi lebih besar dan menutupi seluruh permukaan [23]. Penurunan persentase porositas ini disebabkan karena betambahnya kadar aspal yang menutupi pori dalam campuran, sehingga prosentasi pori atau rongga udara dalam campuran semakin kecil.

\section{Uji Kuat Tekan}

Pengujian sifat mekanik kuat tekan dilakukan pada semua sampel yaitu SA0; SA07; SA08; dan SA09. Hasil uji kuat tekan ditunjukkan pada Gambar 5.

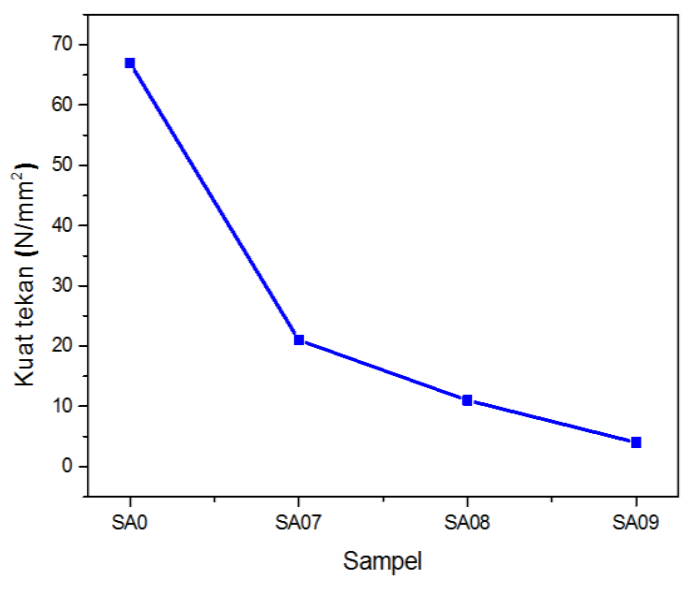

Gambar 5. Grafik hasil uji kuat tekan

Hasil analisis menunjukkan bahwa terjadi penurunan yang drastis dari sampel SA0 hingga sampel SA07 sebesar $46 \mathrm{~N} / \mathrm{mm}^{2}$, dari sampel SA07 kemudian turun sekitar 7-10 $\mathrm{N} / \mathrm{mm}^{2}$ hingga sampel SA09.

Sampel SA0 memiliki nilai kuat tekan paling tinggi dibandingkan dengan sampel lain. Hal ini sesuai dengan karakteristik silika sekam padi yaitu memiliki kekerasan yang tinggi [24]. Sampel SA07; SA08; dan SA09 mengalami penurunan nilai kuat tekan yang disebabkan oleh aspal yang memiliki sifat viskoelastis. Penambahan aspal menyebabkan penurunan nilai kuat tekan yang juga diikuti dengan bertambahnya komposisi unsur karbon dalam sampel.

\section{KESIMPULAN}

Berdasarkan hasil penelitian maka dapat disimpulkan bahwa dengan penambahan aspal terbentuk fasa amorf dengan puncak silika dan karbon yang menyebabkan perubahan pada difraktogram puncak silika $2 \theta=22^{\circ}$ menjadi $2 \theta=20^{\circ}$. Selain itu, struktur mikro silika berubah dengan adanya retakan (cracking) serta gumpalan (cluster) semakin besar dengan ukuran butir masing-masing 7,742 $\mu \mathrm{m}, 8,495 \mu \mathrm{m}$ dan 10,921 $\mu \mathrm{m}$. Hasil EDS menunjukkan bahwa penambahan aspal menyebabkan persentase kadar silikon $(\mathrm{Si})$, Oksigen $(\mathrm{O})$ dan natrium $(\mathrm{Na})$ semakin menurun dan persentase kadar karbon (C), 
sulfur (S) semakin meningkat. Hasil FTIR menunjukkan gugus fungsi ikatan $\mathrm{Si}-\mathrm{OH}$, Si-O-Si dan Si-O semakin melemah dan gugus fungsi dari ikatan $\mathrm{C}-\mathrm{H}$ semakin meningkat. Analisis sifat fisis dan mekanik

[1] S. Sembiring and P. Karo-Karo, "Pengaruh Suhu Sintering Terhadap Karakteristik Termal Dan Mikrostruktur Silika Sekam Padi," Jurnal Sains dan Teknologi., vol. 13, no. 3, pp. 233-239, 2007.

[2] S. Sembiring, W. Simanjuntak, R. Situmeang, and A. Riyanto, "Preparation of refractory cordierite using amorphous rice husk silica for thermal insulation purposes Preparation of refractory cordierite using amorphous rice husk silica for thermal insulation purposes," Ceram. Int., vol. 42, no. 7, pp. 8431-8437, 2016.

[3] S. Sembiring, W. Simanjuntak, P. Manurung, D. Asmi, and I. M. Low, "Synthesis and characterisation of gel-derived mullite precursors from rice husk silica," Ceram. Int., vol. 40, no. 5, pp. 7067-7072, 2014.

[4] H. A. Prasetya, "Untuk Pembuatan Kampas Rem Menggunakan Bahan Karet Alam Use Of Silica Nano Rice Husk For Asbestos Substitution On Motor," Karet dan Plastik. vol 1. pp. 153-162, 2016.

[5] Nasruddin, "Pemanfaatan silika abu sekam padi sebagai bahan pengisi rubber membrane filter press untuk memisahkan minyak inti sawit," Dinamika Penelitian Industri, vol. 23, no. 2, pp. 107-115, 2012.

[6] W. Sugiyo, F. W. Mahatmanti, and M. Alauhdin, "Sintesis Komposit Kitosan-Silika Dan Aplikasinya Sebagai Adsorben Zat Warna Tektil," Sainteknol, vol. 9, no. 1, pp. 21-32, 2011.

[7] F. P. Syahrani, E. E. Ernawati, and R. menunjukkan bahwa terjadi peningkatan nilai densitas serta penurunan nilai porositas dan kuat tekan.

\section{DAFTAR PUSTAKA}

Tjokronegoro, "Pembuatan Komposit Selulosa Asetat-Silika Sekam Padi," Prosiding Seminar Nasional MIPA. pp. 27-28, 2016.

[8] C. Ouyang, S. Wang, Y. Zhang, and Y. Zhang, "Low-Density Polyethylene / Silica Compound Modified Asphalts with HighTemperature Storage Stability," Journal of Applied Polymer Science. vol. 101. pp. 472-479, February, 2005.

[9] X. Guo, M. Sun, W. Dai, and S. Chen, "Performance characteristics of silane silica modified asphalt," Adv. Mater. Sci. Eng., vol. 11, pp. 1-7, 2016.

[10] M. Enieb and A. Diab, "ScienceDirect Characteristics of asphalt binder and mixture containing nanosilica," Int. J. Pavement Res. Technol., vol 10. no. 10, pp. 148-157, 2017.

[11] L. Budiawati, "Pengaruh Penambahan Silika Sekam Padi Terhadap Sifat Fisik dan Struktur Fasa Aspal," Universitas Lampung, 2019.

[12] S. Isma, "Karakteristik Fungsional Dan Sifat Fisis Aspal Akibat Penambahan Silika Sekam Padi," Universitas Lampung, 2019.

[13] T. H. Liou and C. C. Yang, "Synthesis and surface characteristics of nanosilica produced from alkaliextracted rice husk ash," Mater. Sci. Eng. B Solid-State Mater. Adv. Technol., vol. 176, no. 7, pp. 521529, 2011.

[14] E. Rafiee, S. Shahebrahimi, M. Feyzi, and M. Shaterzadeh, "Optimization of synthesis and characterization of 
nanosilica produced from rice husk (a common waste material)," Int. Nano Lett., vol. 2, no. 1, 2012.

[15] P. Deshmukh, J. Bhatt, D. Peshwe, and S. Pathak, "Determination of silica activity index and XRD, SEM and EDS studies of amorphous $\mathrm{SiO} 2$ extracted from rice Husk Ash," Trans. Indian Inst. Met., vol. 65, no. 1, pp. 63-70, 2012.

[16] H. Nazari, K. Naderi, and F. Moghadas Nejad, "Improving aging resistance and fatigue performance of asphalt binders using inorganic nanoparticles," Constr. Build. Mater., vol. 170, pp. 591-602, May 2018.

[17] S. Sembiring, A. Riyanto, R. Situmeang, and Z. Sembiring, "Bituminous Composite Comprising Amorphous Silica," CeramicsSilikáty., vol. 63, no. 3, pp. 277-286, 2019.

[18] E. A. Ningtias, "Pengaruh struktur mikro aspal akibat penambahan silika sekam padi," Universitas Lampung, 2018.

[19] D. O. Larsen, J. Luis, A. Bosch, and M. S. Cortizo, "Micro-structural and rheological characteristics of SBSasphalt blends during their manufacturing," Constr. Build. Mater., vol. 23, no. 8, pp. 2769-2774,
2009.

[20] M. Enieb and A. Diab, "Characteristics of asphalt binder and mixture containing nanosilica," Int. J. Pavement Res. Technol., vol. 10, no. 10, pp. 148-157, 2017.

[21] A. H. Abed and A. M. Oudah, "Rheological properties of modified asphalt binder with nanosilica and SBS," IOP Conf. Ser. Mater. Sci. Eng., vol. 433, no. 1, 2018.

[22] I. W. N. Iskandar, A. Setyawan, and S. J. Legowo, "Sifat-Sifat Marshall Dan Resilient Modulus Pada Thin Surfacing Hot Mix Asphalt Dengan Polymer Modified Bitumen," Matriks Teknik Sipil, vol. 4, no. 36, pp. 591601, 2016.

[23] D. Dahliana, S. Sembiring, and W. Simanjuntak, "Pengaruh Suhu Sintering Terhadap Karakteristik Fisis komposit $\mathrm{MgO}-\mathrm{SiO}_{2}$ berbasis silika sekam padi," Jurnal Teori dan Aplikasi Fisika, vol. 01, no. 01, pp. 14, 2013.

[24] C. J. Brinker and G. W. Scherer, Sol Gel Science The Physics and Chemistry of Sol Gel Processing. USA: Academic Press, 1990. 